\title{
Erratum to: Development, Validation, and Application of a Parametric Pediatric Head Finite Element Model for Impact Simulations
}

\author{
Zhigang Li, ${ }^{1,2}$ Jingwen Hu, ${ }^{1}$ Matthew P. Reed, ${ }^{1}$ Jonathan D. Rupp, ${ }^{1}$ Carrie N. Hoff, ${ }^{3}$ \\ JiNHUAN ZhANG, ${ }^{2}$ and Bo CHENG ${ }^{2}$ \\ ${ }^{1}$ University of Michigan Transportation Research Institute, Ann Arbor, MI, USA; ${ }^{2}$ State Key Laboratory of Automotive Safety \\ and Energy, Tsinghua University, Beijing, China; and ${ }^{3}$ Department of Radiology, University of Michigan, Ann Arbor, MI, USA \\ Erratum to: Annals of Biomedical Engineering (2011) \\ 39(12):2984-2997 \\ DOI 10.1007/s10439-011-0409-z \\ This erratum is to correct for a gantry tilt effect that \\ was not considered in the $\mathrm{CT}$ image processing in the \\ original publication. Figures 3-8, 10-12, and Table 2 \\ have been updated to reflect the geometry changes of \\ the pediatric heads in both the CT segmentation results \\ and the parametric FE model. The $p$-values of material \\ and geometry factors in the parametric study in Fig. 6 \\ changed slightly from the original publication, but \\ these changes did not affect statistical significance. \\ After correction, on average, the model of the 3-month- \\ old head still predicted higher maximal principal \\ stress and strain in the suture than the model of the \\ newborn head, but this age effect dropped from 64.8 \\ to $32.0 \%$ for the stress and from 66.3 to $51.1 \%$ for \\ the strain. Similarly, after correction, the model of the \\ 3-month-old head still predicted lower maximal \\ principal stress and strain in the skull than the model \\ of the newborn head, but the age effect changed from \\ -25.7 to $-35.5 \%$ for the stress and from -11.5 to \\ $-6.2 \%$ for the strain. The optimal material parame- \\ ters shown in Table 2 also changed slightly from \\ the original publication. In particular, the optimal \\ elastic moduli of skull, suture, dura, and scalp were \\ 164.3, 15.8, 17.3, and $8.5 \mathrm{MPa}$, respectively, after \\ correction. \\ The major findings and conclusions of this paper are \\ not affected by these differences. The corrected version \\ of Figs. 3-8, 10-12, and Table 2 are presented here.
}

Address correspondence to Jingwen $\mathrm{Hu}$, University of Michigan Transportation Research Institute, Ann Arbor, MI, USA. Electronic mail: jwhu@umich.edu

The online version of the original article can be found under doi: 10.1007/s10439-011-0409-z. 

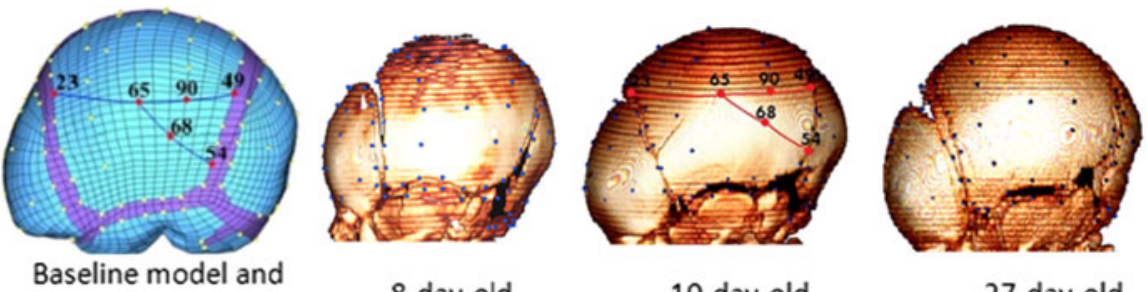

8-day-old

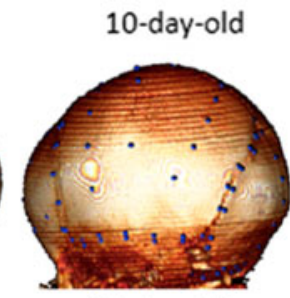

27-day-old
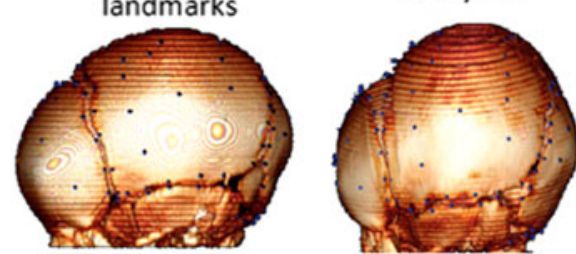

34-day-old

57-day-old

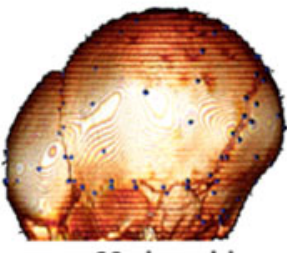

63-day-old
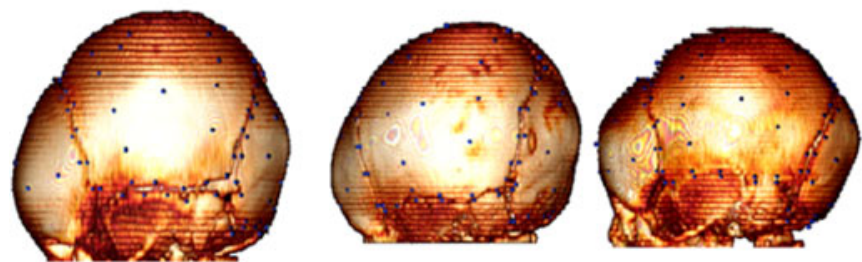

79-day-old

80-day-old

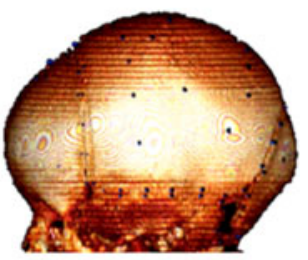

83-day-old

FIGURE 3. Landmarks, baseline FE model, and CT segmentation.

Red point: 3-month-old; Blue point: 1.5-month-old; Black point: Newborn

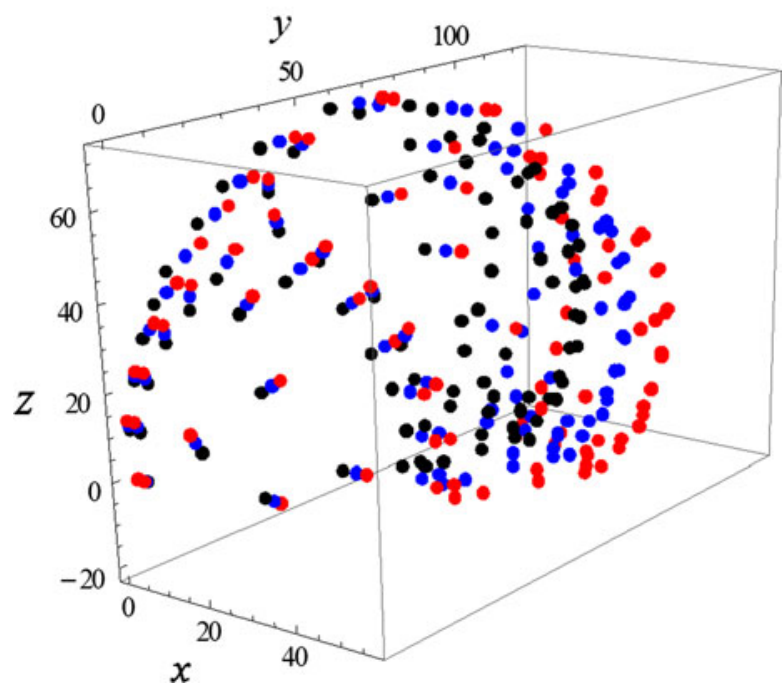

FIGURE 4. Predicted landmark spatial locations for half of the pediatric heads at three ages (unit: $\mathrm{mm}$ ). 


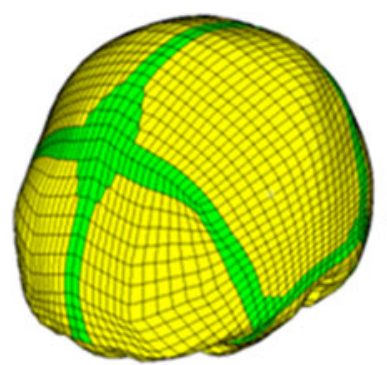

Baseline

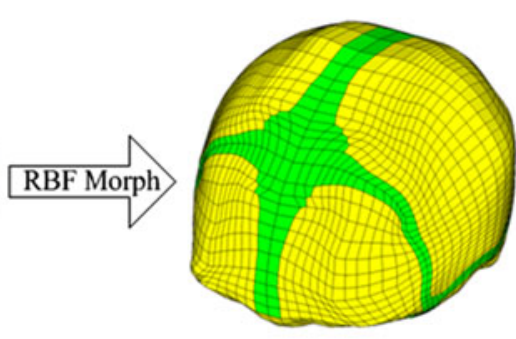

Newborn

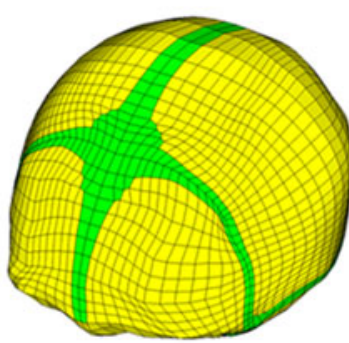

1.5-month-old

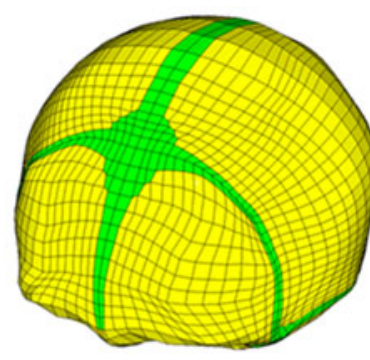

3-month-old

FIGURE 5. Morphing results from baseline model to three targets. 

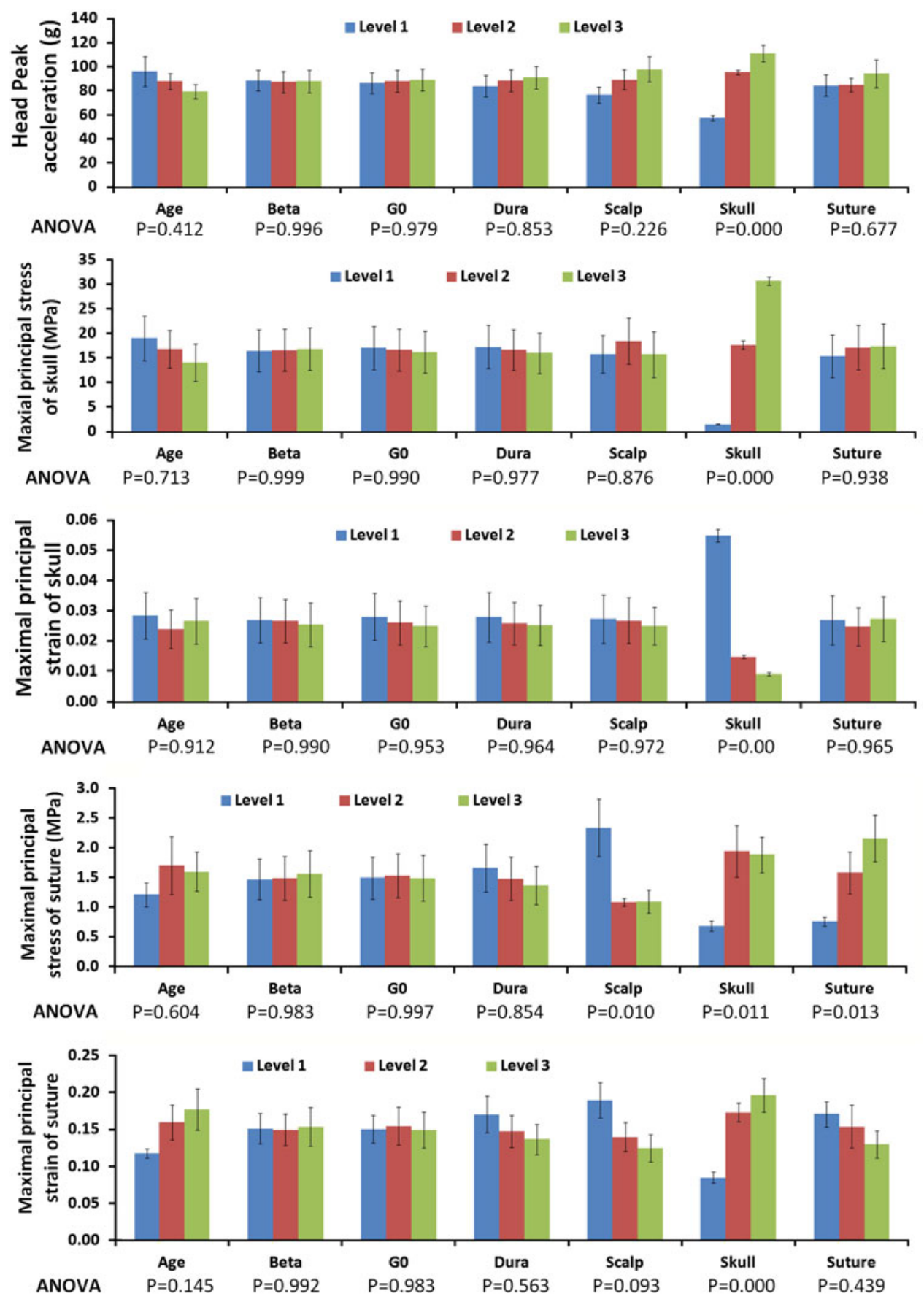

FIGURE 6. Response measurements with respect to all factors. 

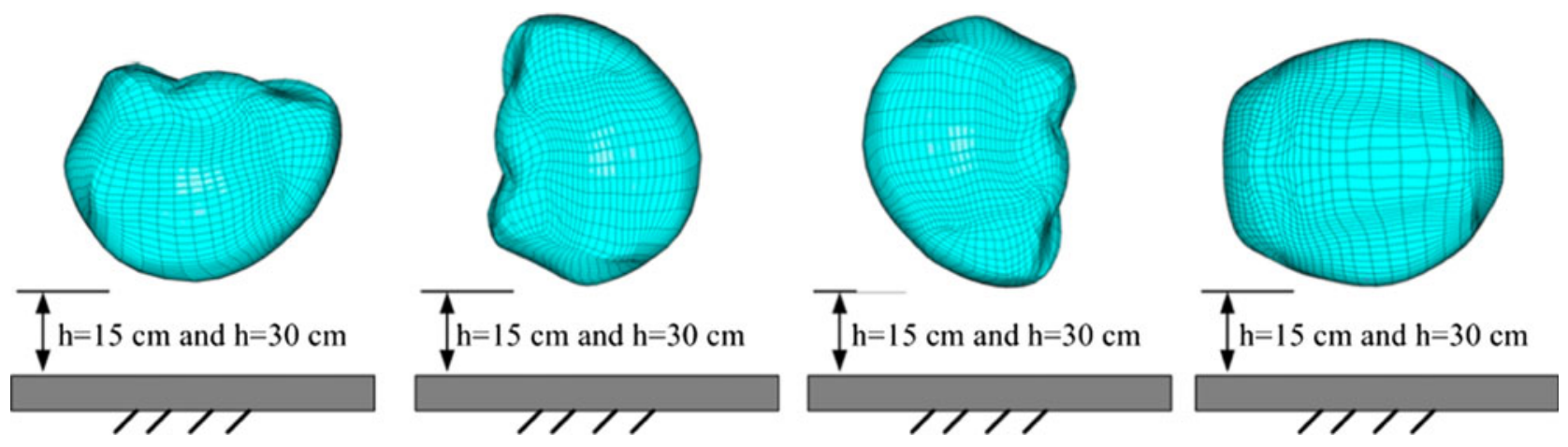

FIGURE 7. Drop test conditions.

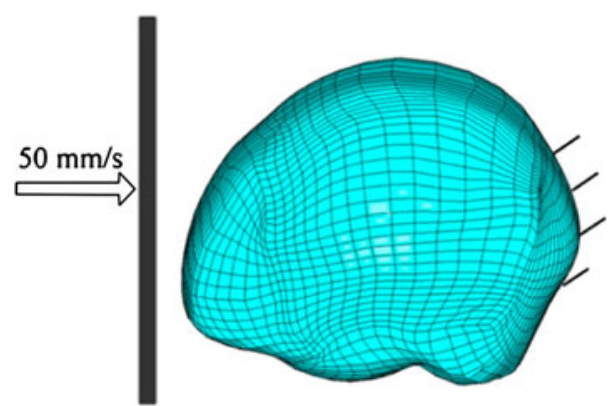

FIGURE 8. Compression test setup with moving plate at the anterior boundary and the posterior skull fixed.

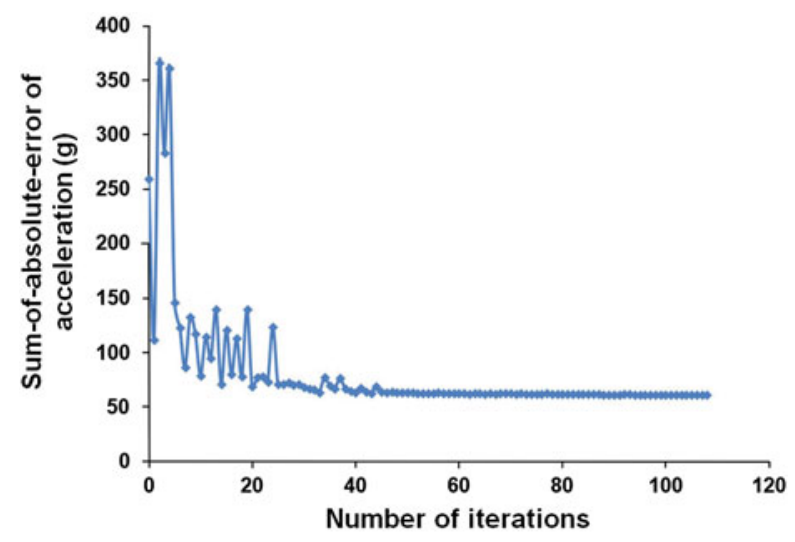

FIGURE 10. History of sum of acceleration errors in eight drop conditions in the optimization. 

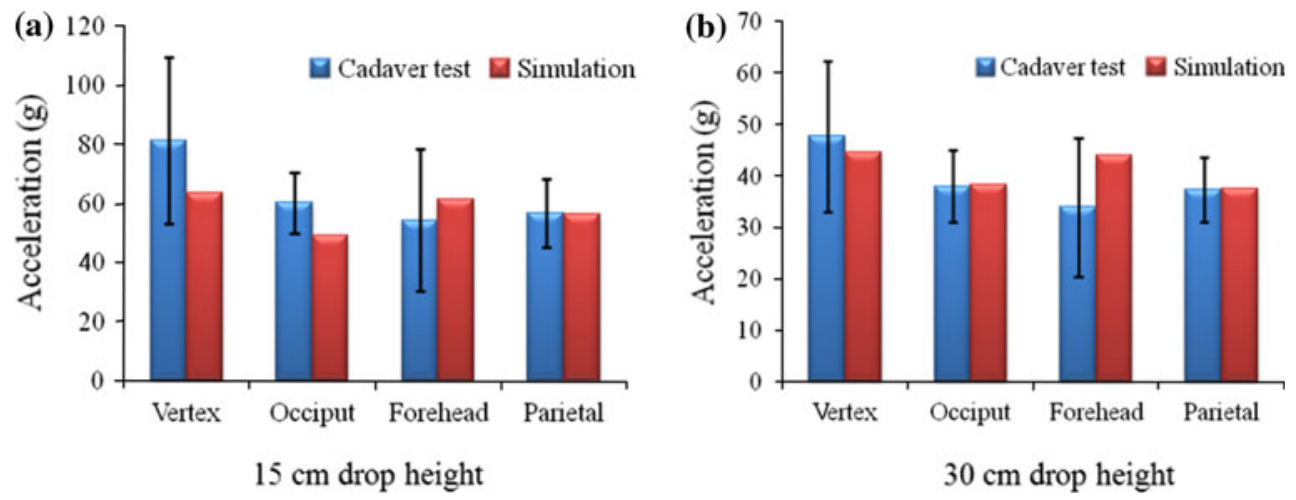

FIGURE 11. Optimization results under different drop conditions.

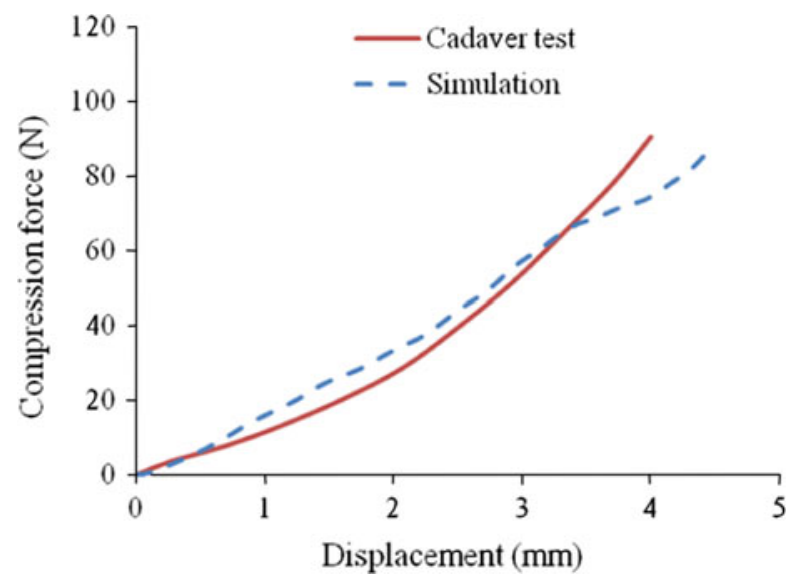

TABLE 2. Material properties used in the infant head FE models.

\begin{tabular}{lcccl}
\hline Parameters & $\begin{array}{c}\text { Young's } \\
\text { modulus }(\mathrm{MPa})\end{array}$ & $\begin{array}{c}\text { Poisson's } \\
\text { ratio }\end{array}$ & $\begin{array}{c}\text { Density } \\
\left(\mathrm{kg} / \mathrm{m}^{3}\right)\end{array}$ & Note \\
\hline Skull & 164.3 & 0.22 & 2150 & Optimization \\
Suture & 15.8 & 0.49 & 1130 & determined \\
Dura & 17.3 & 0.45 & 1140 & \\
Scalp & 8.5 & 0.42 & 1200 & \\
CSF & 0.012 & 0.499 & 1040 & From literature \\
Brain & $K=2.11 \mathrm{GPa}, G(t)=$ & 1040 & \\
& $G_{\infty}+\left(G_{0}-G_{\infty}\right) e^{-\beta t}$ & & \\
& $G_{0}=5.99 \mathrm{kPa}$, & & \\
& $G_{\infty}=2.32 \mathrm{kPa}$, & & \\
& $\beta=35 / \mathrm{s}$ & & \\
\hline
\end{tabular}

FIGURE 12. Test and simulation comparison in compression condition. 